\title{
Update on the pathologic diagnosis of chronic myelomonocytic leukemia
}

\author{
Daniel A. Arber ${ }^{1}$ - Attilio Orazi ${ }^{2}$
}

Received: 19 October 2018 / Revised: 3 January 2019 / Accepted: 12 January 2019 / Published online: 5 February 2019

(c) United States \& Canadian Academy of Pathology 2019

\begin{abstract}
The diagnostic criteria for chronic myelomonocytic leukemia were recently revised in the 2016 World Health Organization classification update and include new and revised subtypes. In addition, molecular genetic studies have provided new insights into the prognosis and diagnosis of this myeloid neoplasm. This review summarizes the 2016 changes to the diagnostic criteria, discusses potential future changes that may impact diagnosis and provides an overview of recent advances in the diagnosis and prognosis determination of chronic myelomonocytic leukemia.
\end{abstract}

\section{Introduction}

The 2016 revision to the World Health Organization (WHO) classification of tumors of hematopoietic and lymphoid tissues includes a revision to the criteria for the diagnosis of chronic myelomonocytic leukemia (CMML) $[1,2]$. CMML is a clonal hematopoietic neoplasm that is more common in elderly patients with a male predominance. By definition, it is associated with monocytosis and was once considered as a subtype of the myelodysplastic syndromes (MDSs). Many cases, however, present with elevated peripheral blood white blood cell (WBC) counts and organomegaly and CMML is now included in the category of myeloproliferative/myelodysplastic neoplasms along with atypical chronic myeloid leukemia (CML), BCR-ABL1-negative, juvenile myelomonocytic leukemia, myelodysplastic (MD)/myeloproliferative neoplasm (MPN) with ring sideroblasts and thrombocytosis, and MD/MPN, unclassifiable [3]. This review will summarize the changes from the 2008 to the 2016 WHO classification in the diagnostic criteria for CMML and describe potential future diagnostic considerations related to the disease.

Daniel A. Arber

darber1@bsd.uchicago.edu

1 Department of Pathology, University of Chicago, Chicago, IL, USA

2 Department of Pathology, Texas Tech Health Sciences Center, El Paso, TX, USA
The overall incidence of CMML in the US is 0.35 cases per 100,000 population [4] and a similar frequency has been reported in a review of the Netherlands Cancer Registry [5]. Over $88 \%$ of patients with CMML are aged $>60$ years at the time of diagnosis with a median age of 75 years. CMML occurs most commonly in white males. The median overall survival of CMML is 12 months; overall survival varies by age but not by gender or ethnicity. Currently, the only curative therapy for CMML is allogeneic stem cell transplantation, but owing to advanced age at presentation such therapy is not available for most patients. Hypomethylating agents (azacitidine and decitabine) are currently the most commonly used therapies for CMML [6].

\section{WHO diagnostic criteria for CMML}

The 2016 WHO criteria for CMML are provided in Table 1 and the cytologic and morphologic features are illustrated in Fig. 1. The diagnosis not only continues to require a peripheral blood monocytosis of $\geq 1 \times 10^{9} / \mathrm{L}$ but now also requires that at least $10 \%$ of peripheral blood white cells be monocytes. This change simply removes some ambiguity in the diagnostic criteria. The early descriptions of CMML by the French-American-British cooperative group (FAB) required $1.0 \times 10^{9} / \mathrm{L}$ and at least $3 \%$ peripheral blood monocytes and said that most cases had monocyte counts $>10 \%$ [7]. Both the Third edition of the WHO Classification in 2001 and the Fourth edition in 2008 stated that peripheral blood monocytes were "almost always $>10 \%$ " $[8,9]$ but a specific percentage required for diagnosis was not clearly stated in those editions. The current change to require $>10 \%$ 
Table 1 WHO 2016 diagnostic criteria for chronic myelomonocytic leukaemia

- Persistent PB monocytosis $\geq 1 \times 10^{9} / \mathrm{L}$ and $\geq 10 \%$ of the leukocytes

- Not meeting WHO criteria for BCR-ABL1-positive CML, primary myelofibrosis, polycythemia vera or essential thrombocythemia ${ }^{\mathrm{a}}$

- No evidence of PDGFRA, PDGFRB, or FGFR1 rearrangement or $P C M 1-J A K 2$ (should be specifically excluded in cases with eosinophilia)

- Fewer than $20 \%$ blasts in the blood and bone marrow ${ }^{\mathrm{b}}$

- Dysplasia in one or more myeloid lineages. If myelodysplasia is absent or minimal, the diagnosis of CMML may still be made if the other requirements are met and

- an acquired clonal cytogenetic or molecular genetic abnormality is present in hematopoietic cells ${ }^{\mathrm{c}}$

or

- the monocytosis has persisted for at least 3 months and

- all other causes of monocytosis have been excluded

$C M L$ chronic myeloid leukemia, $C M M L$ chronic myelomonocytic leukemia, $P B$ peripheral blood, $W H O$ World Health Organization

${ }^{\mathrm{a}}$ Cases of myeloproliferative neoplasm (MPN) can be associated with monocytosis or they can develop it during the course of the disease. These cases may simulate CMML. In these rare instances, a previous documented history of MPN excludes CMML, while the presence of MPN features in the bone marrow (BM) and/or of MPN-associated mutations (JAK2, CALR, or MPL) tend to support MPN with monocytosis rather than CMML.

${ }^{\mathrm{b}}$ Blasts and blast equivalents include myeloblasts, monoblasts, and promonocytes. Promonocytes are monocytic precursors with abundant light gray or slightly basophilic cytoplasm with a few scattered, fine lilac-colored granules, finely distributed, stippled nuclear chromatin, variably prominent nucleoli, and delicate nuclear folding or creasing. Abnormal monocytes, which can be present both in the PB and BM, are excluded from the blast count

${ }^{\mathrm{c}}$ The presence of mutations in genes often associated with CMML (e.g., TET2, SRSF2, ASXL1, SETBP1) in the proper clinical contest can be used to support a diagnosis. It should be noted, however, that many of these mutations can be age related or be present in subclones. Therefore, caution would have to be used in the interpretation of these genetic results.

monocytes will help to exclude patients with high WBC counts due to other etiologies that may have small monocyte components that nevertheless meet the $1 \times 10^{9} / \mathrm{L}$ threshold.

The diagnostic criteria continue to require exclusion of CML, BCR-ABL1-positive, and rare cases of CML with the p190 BCR-ABL1 fusion product may present with monocytosis and mimic CMML [10]. The criteria now more clearly require exclusion of other MPNs, including primary myelofibrosis, polycythemia vera, and essential thrombocythemia. Primary myelofibrosis, in particular, may develop or have coexisting monocytosis, which is a poor prognostic factor in that disease [11-14]. When monocytosis develops in the course of the disease, it may be considered equivalent to an accelerated phase. Monocytosis seen in patient with polycythemia vera may also be associated with a worse prognosis than in patients without monocytosis [15]. The presence of morphologic features on the bone marrow of a MPN and the presence of mutations (JAK2, CALR, and $M P L)$ associated with MPNs would support a diagnosis of the MPN with associated monocytosis over a diagnosis of CMML.

In addition to the MPNs, cases suggestive of CMML but with coexisting eosinophilia must also have the various genetic subgroups of myeloid/lymphoid neoplasms with eosinophilia and gene rearrangements excluded. These genetic abnormalities include fusions of PDGFRA, PDGFRB, FGFR1, and PCM1-JAK2 [16]. Fusions involving PDGFRA, usually FIPIL1-PDGFRA, are often cryptic and may be missed by routine karyotype analysis. Particularly relevant to the differential diagnosis of CMML is the fusion of ETV6-PDGFRB produced by the $\mathrm{t}(5 ; 12)(\mathrm{q} 32$; p13.2) resulting in a neoplasm with both monocytosis and eosinophilia that was originally considered a subtype of CMML but is now considered a separate entity within the group of myeloid/lymphoid neoplasms with eosinophilia and gene rearrangements. Similarly to cases associated with FIPIL1-PDGFRA, it also responds to tyrosine kinase inhibitor therapy [17].

The diagnosis of CMML still requires that $<20 \%$ blasts and promonocytes (the latter are blast equivalent cells) be present in both the peripheral blood and bone marrow. Bone marrow examination is required to exclude acute leukemia and to confirm CMML. The ability to distinguish blasts and promonocytes from abnormal monocytes can be challenging but is essential for proper diagnosis. Figure 2 illustrates the morphologic features of each. Monoblasts have roundto-oval nuclei with minimally to un-vacuolated, bluestaining cytoplasm on Romanowsky-stained smears [18]. The blast nucleus has fine nuclear chromatin, often with distinct nucleoli. In contrast, mature monocytes have folded nuclei with vacuolated, blue-gray or pale pink staining cytoplasm and clumped nuclear chromatin without nucleoli. A promonocyte has nuclear folding and may have cytoplasmic vacuoles, similar to a mature monocyte, but immature nuclear chromatin with or without nucleoli. When considering a diagnosis of CMML or any monocytic or myelomonocytic leukemia, blasts and promonocytes must be counted together as blast cell equivalents. Not all blasts in CMML are monoblasts and promonocytes; poorly differentiated myeloid blasts can also be identified.

The final change to the 2016 WHO criteria for diagnosis is reflected in a footnote related to the use of gene mutations in the diagnosis. CMML can be diagnosed without a clonal genetic abnormality when dysplasia affecting at least one cell line is present or when monocytosis persists for at least 3 months and all reactive and paraneoplastic causes of monocytosis are excluded. In the absence of dysplasia, the presence of a clonal cytogenetic abnormality can be 


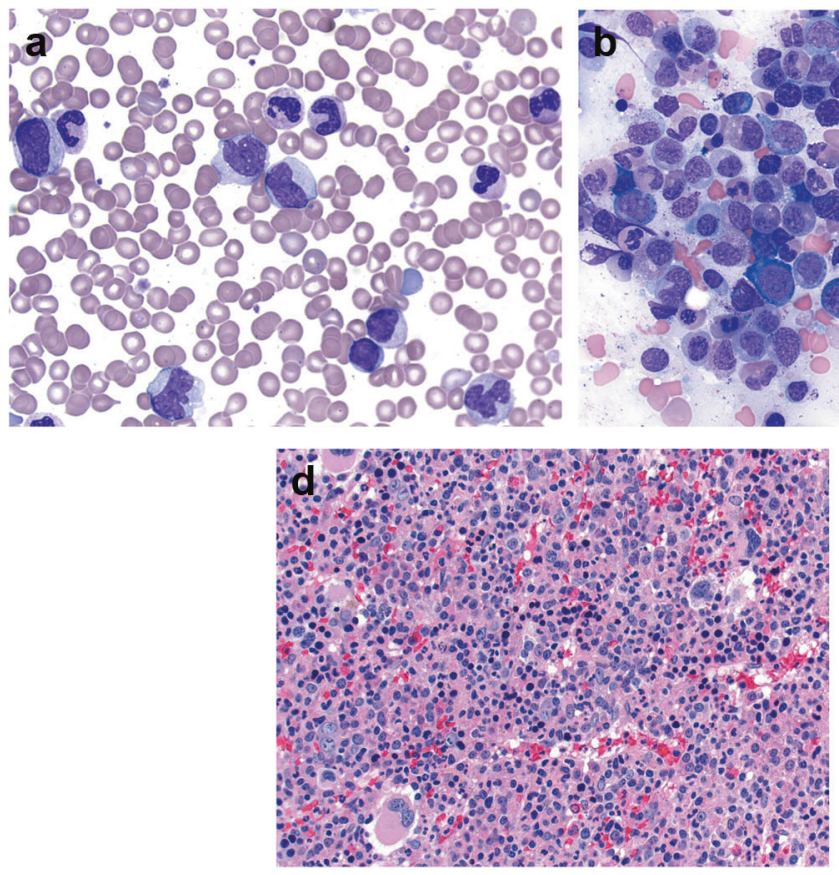

Fig. 1 a The peripheral blood in chronic myelomonocytic leukemia must demonstrate monocytosis of $\geq 1 \times 10^{9} / \mathrm{L}$ with at least $10 \%$ monocytes. Dysplastic changes, such as clumped nuclear chromatin of neutrophils in this case, may also be present. b The bone marrow aspirate has a granulocye/monocyte predominance in which the monocytic cells may not be obvious. Background dysplastic changes, as seen here in the erythroid precursors and megakaryocytes, are also

sufficient for diagnosis. Only approximately $30 \%$ of CMML cases, however, have a clonal cytogenetic abnormality with trisomy 8 with or without additional abnormalities and isolated loss of $\mathrm{Y}$ being the most common. Complex karyotypes and chromosome 7 abnormalities are less common but are associated with a poor prognosis $[19,20]$.

The use of molecular genetic abnormalities in the diagnosis has been somewhat clarified compared to 2008 . This reflects the increased use of next-generation sequencing in the diagnostic/prognostic assessment of myeloid neoplasms. Most patients with CMML have associated gene mutations, with mutations of $S F R S F 2$, TET2, ASXL1, RUNX1, SETBP1, RAS family genes, and EZH2 being most common [21-24]. With extensive sequencing, most patients have mutations of multiple genes, a finding that may be useful for diagnosis with a few caveats. Clonal hematopoiesis of indeterminate prognosis (CHIP) [25-27] occurs in a high percentage of older adults, the same demographic that may develop CMML, but the presence of CHIP mutations is not predictive for development of CMML. Moreover, some CHIP-associated mutations (specifically TET2 and ASXL1) are common both in CHIP and in CMML. However, in the correct clinical setting (i.e., in a cytopenic patient with monocytosis), the detection of multiple
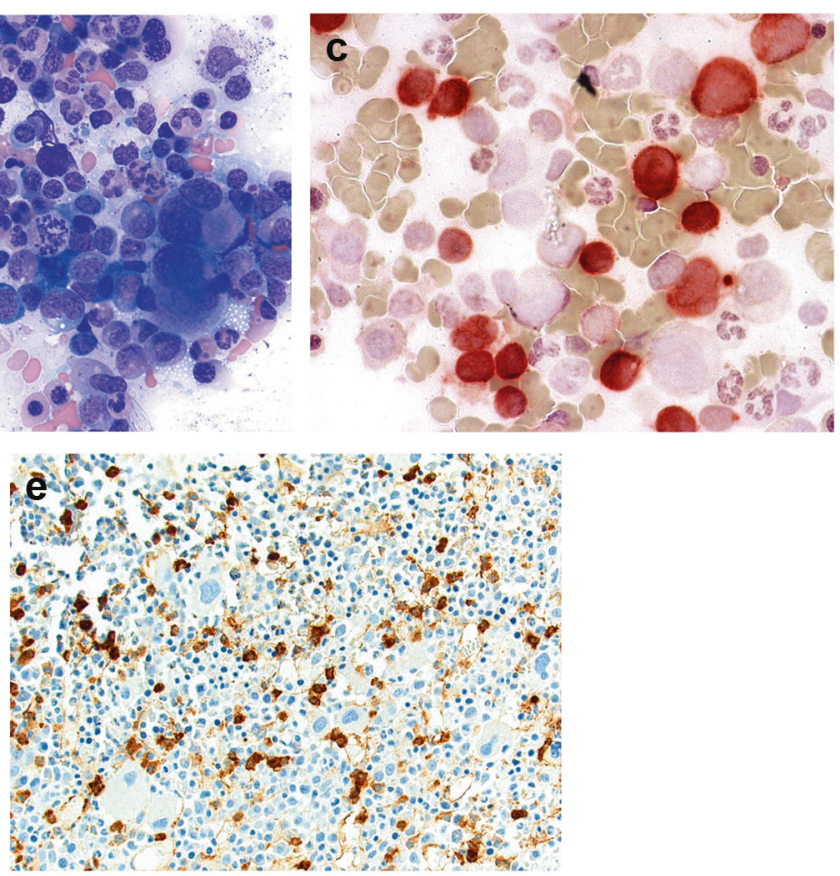

often present. c Cytochemical studies for non-specific esterase will often identify more monocytic cells than suspected on the bone marrow aspirate. $\mathbf{d}$ The bone marrow biopsy is typically hypercellular with a mixed cellular composition. e Immunohistochemsitry for CD14 may highlight increased monocytes not suspected on the hematoloxylin \& eosin-stained biopsy

mutations especially if inclusive of TET2 and SRSF2 can be of help in supporting a diagnosis of CMML.

\section{CMML subtypes}

The 2016 WHO classification expands the number of CMML subtypes based on blast cell count from two to three (see Table 2) with the addition of CMML-0. CMML-0 is defined as $<2 \%$ blasts in the blood and $<5 \%$ in the bone marrow. These cases were previously included in CMML-1. The category of CMML-2 is unchanged. The addition of CMML-0 is based largely on studies considering the prognostic impact of peripheral blood blasts in CMML. Onida and colleagues [28, 29] demonstrated improved survival in CMML when no peripheral blast cells were present and Schuler et al. showed improved survival in patients with $<2 \%$ peripheral blood blasts using the scheme that is now adopted by the WHO. However, using the Spanish Registry of MDS, Xicoy and colleagues [30] recently found no difference between CMML-0 and CMML-1 in a cohort of 859 patients. It should be mentioned, however, that the Spanish Registry study contained a higher rate of low-risk cytogenetics and higher rates of MD-type CMML (see later) than the study by Schuler et al. In a recent study from MD Anderson Cancer Center, the 


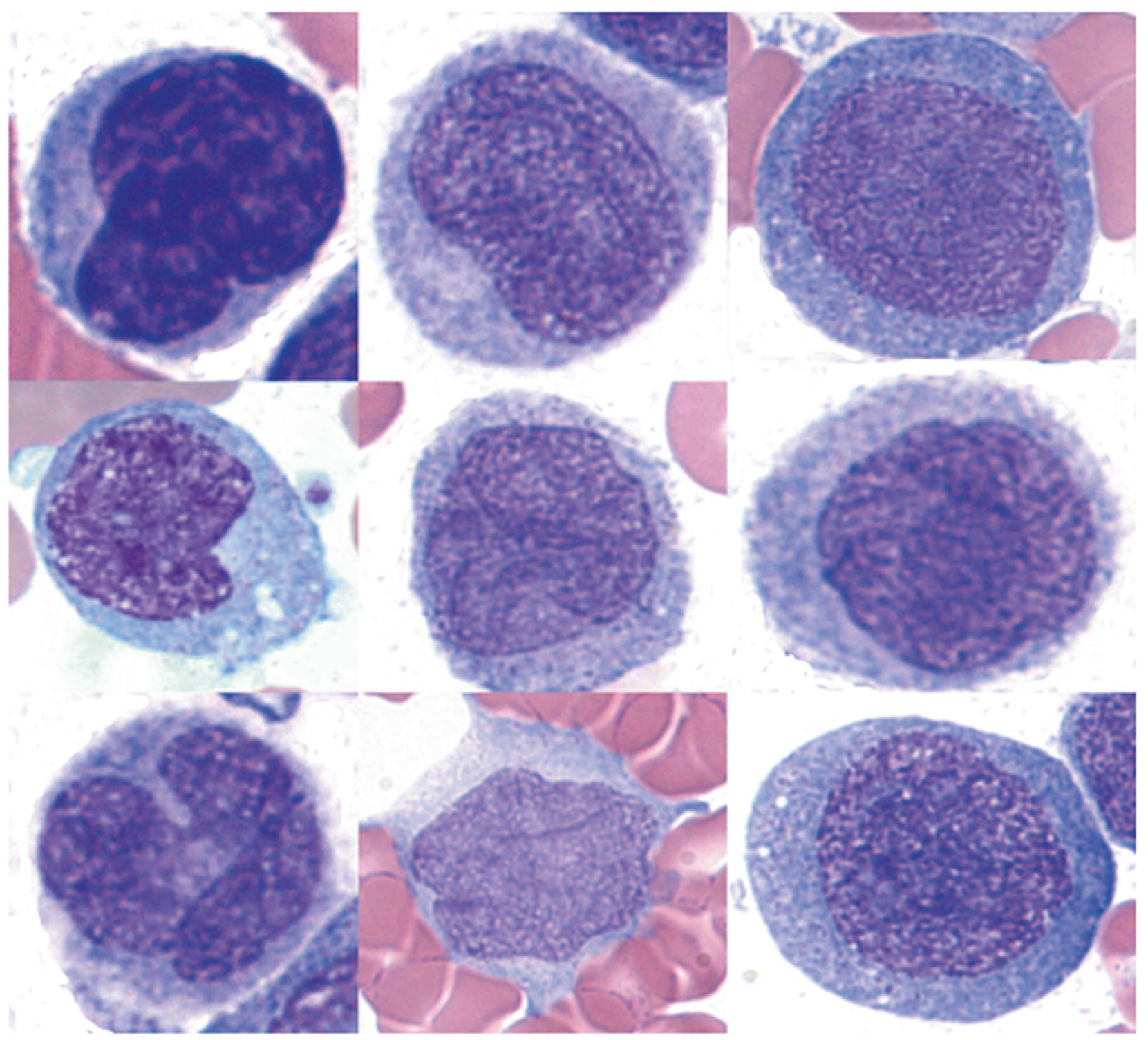

Fig. 2 The spectrum of monocytes in chronic myelomonocytic leukemia. The left column illustrates abnormal monocytes that do not meet criteria for promonocytes (blast cell equivalents) or monoblasts. Monoblasts are illustrated in the right column. The middle column shows the variation in promonocytes, with fine nuclear chromatin,

2016 WHO CMML blast categories were not associated with acute myeloid leukemia-free survival. Only a marginal difference in overall survival $(P=0.0552)$ was identified between the CMML-0 and CMML-1 groups in treatmentnaive patients, and CMML-0 more significantly correlated with overall survival $(P=0.0278)$ compared to CMML-1 for patients with MP-type CMML [31]. The MD Anderson study also had a slightly higher rate of MD-type CMML. These data underline the limitations of a single parameter determination and suggest that a multifactorial approach to risk stratification is needed and that perhaps geographic differences may also play a role in the utility to predict prognosis in CMML. similar to monoblasts, but nuclear folds more common in normal and abnormal monocytes. The recognition of promonocytes is essential for differentiatiing chronic myelomocytic leukemia from acute monocytic/ monoblastic leukemia. The latter diagnosis is made when blasts plus promonocytes are $\geq 20 \%$ in the blood or bone marrow

Further separating CMML into MD and MP subtypes has been controversial. The FAB proposed such designations with the MD group defined by a WBC count of $<13 \times 10^{9} / \mathrm{L}$ and the MP group defined by a WBC count $>13 \times 10^{9} / \mathrm{L}$ [7]. While dysplastic changes may be more common in the MD group, they may also be seen in the MP group. Recent studies comparing CMML patients based on these WBC parameters have shown a significantly worse outcome for patients with the MP type of CMML [28, 29, 31-33]. This outcome difference was also seen within the CMML-0, CMML-1, and CMML-2 subtypes [29]. Based on these data, the 2016 WHO classification recommends further subdividing cases of CMML into MD and MP subtypes. 


\section{Future directions in the pathologic diagnosis or CMML}

While the 2016 WHO classification of CMML captures some changes related to the disease, the study of CMML is ongoing and additional advances have been made that may impact future classification. These discoveries span the spectrum of morphology, immunophenotyping, and molecular genetics. While some were already described at the time of the 2016 revision, the WHO process prefers to wait for new findings to be confirmed in the published literature before incorporating potential new findings.

\section{Morphology}

As previously stated, the 2016 WHO classification created new blast cell cut-offs for the category of CMML-0, but few studies have looked at the blast cell cut-off for distinguishing CMML-1 from CMML-2. Padron et al. [34] evaluated a number of factors in a cohort of 1832 cases of CMML, including the prognostic significance of bone marrow blasts. In this patient population, a bone marrow blast cell count of $\geq 7.5 \%$ was a better predictor of worse overall survival than the traditional $10 \%$. Loghavi et al. also evaluated the optimal blast cell cut-off related to overall survival and identified $8 \%$ as ideal in their entire cohort, but when only treatment-naive patients were considered, a $10 \%$ cut-off correlated best with overall survival [33]. Further studies would be necessary to confirm whether a change in the marrow criteria for CMML-2 is warranted.

While subtyping CMML in MD and MP types has shown prognostic significance in several studies, as summarized above, a recent multi-institutional study has suggested refinements to the $13 \times 10^{9} / \mathrm{L}$ WBC threshold and have proposed a three-tier categorization: an $\mathrm{MD}$ type defined as a WBC count of $<10 \times 10^{9} / \mathrm{L}$ with no peripheral blood immature myeloid cells and no splenomegaly; a mixed MD/MP type with either $10-20 \times 10^{9} / \mathrm{L}$ WBCs or WBC $<10 \times 10^{9} / \mathrm{L}$ but the presence of peripheral blood immature myeloid cells or splenomegaly; and an MP type with $>20 \times 10^{9} / \mathrm{L}$ WBCs [35]. This approach resulted in a prognostic difference for all three groups, with a worse prognosis for the MP group, the best prognosis for the MD group, and an intermediate prognosis for the mixed group. Mutational differences were also present between groups with less frequent $S R S F 2$, ASXL1, and RAS family mutations occurring in the MD type.

The presence of fibrosis in CMML (CMML-F) has been recently studied in detail by several groups. The frequency of fibrosis in CMML varied greatly in these studies, and some studies accepted any degree of fibrosis (i.e., at least MF1) for inclusion, while others only accepted MF2 fibrosis. The fibrosis criteria used, however, do not appear to entirely explain the variation in incidence. Petrova-Drus et al. [36] found $>M F 1$ fibrosis in $54 \%$ of 84 patients with CMML; this was associated with increased splenomegaly, increased bone marrow megakaryocytes, and decreased progression-free survival but had no impact on overall survival and no correlation with JAK2 V617F gene mutations. Khan et al. [37] found fibrosis (>MF2) in CMML to be associated with decreased hemoglobin levels, increased numbers of ring sideroblasts, and, on multivariate analysis, decreased overall survival but no significant impact on event-free survival. In contrast, Gur and colleagues [38] found $>$ MF2 marrow fibrosis in only 3\% of 651 CMML cases studied, which was associated with higher WBC counts, higher serum lactate dehydrogenase levels, and a high frequency of JAK2 V617F gene mutations. The presence of fibrosis in this study, in contrast to the second of the two other studies on fibrosis in CMML, did not impact overall survival. The discrepant findings of the latter study that included an unusually high number of cases associated with JAK2 V617F gene mutations (50\%), compared to 5.7\% in the Petrova-Drus et al. study that allowed a lower level of fibrosis and $1.4 \%$ in the Khan et al. study that used the same fibrosis criteria, are somewhat difficult to reconcile. The very low rate of fibrosis in the one study that does not find prognostic significance of fibrosis in CMML as well as the significantly higher rate of JAK2 mutations in the latter study suggests a difference in the case types studied. These differences raise the possibility that cases of primary myelofibrosis with monocytosis, mimicking CMML, may have been included in the latter study and impacted the results. Another recent report of patients with morphologic and molecular genetic features intermediate between CMML and primary myelofibrosis [14] raises the possibility of an additional morphologic subtype or a "gray zone" myeloid disease overlapping two diagnostic groups MDS/MPN and classical MPN. While the data are not yet conclusive, the presence of marrow fibrosis in CMML may be of prognostic importance and can cause diagnostic difficulties. The incidence and significance of this finding is worthy of more study.

Recently, a series of patients with so-called "oligomonocytic chronic myelomonocytic leukemia" were described with blood monocytes $\geq 10 \%$ of the WBCs, but only accounting for $0.5-1 \times 10^{9} / \mathrm{L}$ as an absolute value [39]. These patients were significantly younger than traditional CMML controls and had fewer gene mutations than controls. However, 38\% progressed to overt CMML (median time to progression: 12 months) and the gene mutations present were the ones common to CMML (TET2, ASXL1, and SRSF2). These findings raise the possibility of an oligomonocytic CMML that may be currently misdiagnosed as a type of MDS. 
Finally, CMML may occur in association with other hematologic, and possibly non-hematologic, neoplasms. The association of CMML with systemic mastocytosis is well known and is a relatively common occurrence in systemic mastocytosis with an associated hematologic neoplasm (SM-AHM). Many of the myeloid types of SM-AHM are clonally related, but the prognosis of SM-AHM is generally believed to be driven by the non-mast cell disorder. CMML associated with systemic mastocytosis, however, appears to have a worse prognosis than similar case without mast cell disease despite a relatively low rate of transformation to acute leukemia [40]. A clonal relationship between mature plasmacytoid dendritic cells, aggregates of which are relatively common in CMML, and myeloid disorders was described over a decade ago [41]. Recently, however, clonally related dual neoplasms of CMML and blastic plasmacytoid dendritic cell neoplasm have also been described [42], suggesting the possibility of more neoplastic cell plasticity than has been previously appreciated.

\section{Immunophenotyping}

Flow cytometry has historically been of limited utility in the diagnosis of CMML due to the lack of specific markers for neoplastic monocytes. CD56 expression is often present on CMML monocytes but may also be seen with other myeloid neoplasms and may be detected in reactive monocytes, especially after prior therapy or growth factor administration [43, 44]. In 2015, Seligmoglu-Buet and colleagues [45] reported that the presence of high $(>94 \%)$ proportions of MO1 monocytes in the peripheral blood was a strong predictor of CMML. MO1 monocytes express CD14 but lack CD16. The presence of $>94 \%$ of this cell population in the blood was a better predictor of CMML than the $1 \times 10^{9} / \mathrm{L}$ cut-off currently used by the WHO. Since the publication by Seligmoglu-Buet et al., other groups have demonstrated similar findings (See Table 2) [46-48]; but one report found an increase in MO1 monocytes in atypical CML, $B C R-A B L 1$-negative [48]. If such testing moves to routine use, this type of immunophenotyping may become an additional useful tool in diagnosing CMML in the correct clinical and pathologic setting, including the so-called "oligomonocytic" CMML subtype [49].

\section{Molecular genetics}

f specific genes in CMML differ in their freIncorporating molecular genetic changes into the diagnostic approach to CMML will become increasingly important as we learn more about these genes and their interactions. Table 3 summarizes the reported frequency of various mutations in CMML. While the detection of so-called CHIP genes (DNMT3A, ASXL1, TET2) may not be particularly useful in the primary diagnosis of CMML, once a diagnosis of CMML is made detection of mutations in ASXL1 is a poor prognostic indicator, associated with significantly decreased overall survival $[22,32,50,51]$. Mutations in SRSF2 [22, 52], RUNX1 [32, 51, 53], SETBP1 [51], RAS pathway genes [22, 31, 51], EZH2 [22], CBL [53], and DNMT3A [54] have also been reported as independent poor prognostic indicators, although $D N M T 3 A$ mutations are relatively uncommon in CMML. Additionally, some gene combinations are known to impact prognosis. For example, mutations of EZH2 in conjunction with ASXL1 mutations are associated with an even worse prognosis [55] while mutations in TET2 in the absence of ASXL1 mutations are associated with an improved prognosis [56]. The total number of mutations also impacts prognosis, with the presence of seven or more mutations significantly associated with worse overall survival [21]. Similarly, mutations involving four or more pathways are associated with decreased overall survival [32].

Gene mutations may assist in more clearly defining the MP versus MD subtypes of CMML rather than relying solely on the peripheral blood WBC count. Mutations of $S F 3 B 1$ and $U 2 A F 1$ are most commonly associated with MD-type CMML [23] and mutations of TET2, SRSF2, RUNX1, NRAS, KRAS, and EZH2 are most commonly associated with the MP subtype [23, 31, 32, 55]. Mutations of $N P M 1$, although relatively uncommon, are associated not only with both high WBC counts (MP subtype) [57] but also with dysplasia [57, 58]. Late occurring mutations in NPM1 in CMML are associated with fairly rapid progression to acute leukemia and a poor prognosis [59]. Despite these possible molecular genetic correlations with subtypes of CMML, the WHO classification currently distinguishes MP versus MD subtypes solely based on the WBC count.
Table 2 Monocyte types in chronic monocytic leukemia compared to reactive monocytosis, controls and other neoplasms [45, 47]

\begin{tabular}{lllllll}
\hline $\begin{array}{l}\text { Monocyte } \\
\text { type }\end{array}$ & Immunophenotype & Controls & $\begin{array}{l}\text { Reactive } \\
\text { monocytosis }\end{array}$ & $\begin{array}{l}\text { Other } \\
\text { hematologic } \\
\text { neoplasms }\end{array}$ & $\begin{array}{l}\text { Chronic } \\
\text { myelomonocytic } \\
\text { leukemia }\end{array}$ & \\
\hline MO1 & CD14+/CD16- & $84-87 \%$ & $79 \%$ & $84 \%$ & $>94 \%$ & $\mathrm{P}<0.001$ \\
MO2 & CD14+/CD16+ & $4 \%$ & a & a & $2 \%$ & $1 \%$ \\
MO3 & CD14-/CD16+ & $9 \%$ & a & a & $1 \%$ & \\
\hline
\end{tabular}

${ }^{\mathrm{a}}$ Variation in results with no mean/median reported 
Table 3 Frequency of gene mutations in chronic myelomonocytic leukemia [21, 22, 24, 51, 57, 58]

\begin{tabular}{|c|c|}
\hline Gene & Reported frequency \\
\hline TET2 & $52-71 \%$ \\
\hline$S R S F 2$ & $36-53 \%$ \\
\hline$A S X L 1$ & $36-52 \%$ \\
\hline$N R A S$ & $10-26 \%$ \\
\hline$C B L$ & $8-24 \%$ \\
\hline RUNX1 & $8-23 \%$ \\
\hline SETBP1 & $9-16 \%$ \\
\hline ZRSR2 & $4-16 \%$ \\
\hline FAT4 & $14.5 \%$ \\
\hline$K R A S$ & $<5-14.5 \%$ \\
\hline$E Z H 2$ & $7-13 \%$ \\
\hline ARIH1 & $12 \%$ \\
\hline CSMD1 & $10 \%$ \\
\hline DNAH2 & $10 \%$ \\
\hline CREBBP & $9 \%$ \\
\hline $\mathrm{SH} 2 \mathrm{~B} 3$ & $9 \%$ \\
\hline UMODL1 & $9 \%$ \\
\hline $\mathrm{CDH} 23$ & $9 \%$ \\
\hline РTCH1 & $9 \%$ \\
\hline$B C R$ & $7 \%$ \\
\hline$K M T 2 D$ & $7 \%$ \\
\hline$N F 1$ & $7 \%$ \\
\hline$I D H 2$ & $6-7 \%$ \\
\hline$J A K 2$ & $5-7 \%$ \\
\hline$S F 3 B 1$ & $5-7 \%$ \\
\hline$U 2 A F 1$ & $4-7 \%$ \\
\hline CBFA2T3 & $6 \%$ \\
\hline DNAH7 & $6 \%$ \\
\hline IRS1 & $6 \%$ \\
\hline MAML2 & $6 \%$ \\
\hline$M P L$ & $6 \%$ \\
\hline PCDHB1 & $6 \%$ \\
\hline TRPM1 & $6 \%$ \\
\hline$V C A N$ & $6 \%$ \\
\hline WNK2 & $6 \%$ \\
\hline DNMT3A & $5-6 \%$ \\
\hline$S M C 1 A$ & $5 \%$ \\
\hline$C S F 3 R$ & $4-5 \%$ \\
\hline PTPN11 & $3-5 \%$ \\
\hline NPM1 & $2-5 \%$ \\
\hline ETNK1 & $3 \%$ \\
\hline$B R A F$ & $2 \%$ \\
\hline
\end{tabular}

The molecular genetic findings of CMML also highlight similarities and differences between CMML and possibly related disorders. The mutations of specific genes in CMML differ in their frequency and clinical significance from the common genes mutated in MDSs [60]. Recently, Montalban-Bravo and colleagues [61] compared the clinical significance of genetic changes and gene mutations in cohorts of MDS and mixed MDS/MPN, with the latter group consisting predominately of cases of CMML. While TP53 mutations were associated with a worse prognosis in both groups, mutations of STAG2 impacted prognosis in MDS but not in MDS/MPN and mutations of EZH2 as well as the presence of $\geq 3$ gene mutations impacted the prognosis of MDS/MPN but not of MDS. Interestingly, the presence of $\geq 3$ gene mutations in MDS/MPN did not correlate with the presence of a complex karyotype and suggest the role of more subtle genetic events in CMML as compared to MDS. In contrast, there appear to be genetic similarities between CMML and atypical CML, BCR$A B L 1$-negative (atypical CML). Meggendorfer and colleagues [24] found striking similarities between the two disorders while the genetic profiles of MDS/MPN, unclassifiable and MDS/MPN with ring sideroblasts and thrombocytosis, the two other major adult categories of MDS/MPN, demonstrated significantly different mutation patterns. As mentioned, Hudson et al. [48] identified three cases of atypical CML with $>94 \%$ MO1 monocytes, also suggesting an immunophenotypic overlap between atypical CML and CMML. More studies will be needed to further evaluate whether these currently distinct entities should be considered as related.

\section{Conclusion}

The discovery of new morphologic, immunophenotypic, and molecular genetic features in CMML provide more tools for the pathologist to make an accurate diagnosis and provide important prognostic information to treating physicians. These methods will quickly spread to the diagnostic laboratory and will assist in providing new, more refined criteria for the diagnosis of CMML and possibly of new CMML subtypes.

\section{Compliance with ethical standards}

Conflict of interest The authors declare that they have no conflict of interest.

Publisher's note: Springer Nature remains neutral with regard to jurisdictional claims in published maps and institutional affiliations.

\section{References}

1. Arber DA, Orazi A, Hasserjian R, Thiele J, Borowitz MJ, Le Beau MM, et al. The 2016 revision to the World Health Organization classification of myeloid neoplasms and acute leukemia. Blood. 2016;127:2391-405. 
2. Orazi A, Bennett JM, Germing U, Brunning RD, Bain BJ, Cazzola $\mathrm{M}$, et al. Chronic myelomonocytic leukemia. In: Swerdlow SH, Campo E, Harris NL, et al., editors. WHO Classification of Tumours of Haematopoietic and Lymphoid Tissues. Revised 4th edition. Lyon: International Agency for Research on Cancer; 2017. p. 82-6.

3. Orazi A, Germing U. The myelodysplastic/myeloproliferative neoplasms: myeloproliferative diseases with dysplastic features. Leukemia. 2008;22:1308-19.

4. Guru Murthy GS, Dhakal I, Mehta P. Incidence and survival outcomes of chronic myelomonocytic leukemia in the United States. Leuk Lymphoma. 2017;58:1648-54.

5. Dinmohamed AG, van Norden Y, Visser O, Posthuma EF, Huijgens PC, Sonneveld P, et al. The use of medical claims to assess incidence, diagnostic procedures and initial treatment of myelodysplastic syndromes and chronic myelomonocytic leukemia in the Netherlands. Leuk Res. 2015;39:177-82.

6. Patnaik MM, Tefferi A. Chronic myelomonocytic leukemia: 2018 update on diagnosis, risk stratification and management. Am J Hematol. 2018;93:824-40.

7. Bennett JM, Catovsky D, Daniel MT, Flandrin G, Galton DAG, Gralnick HR, et al. The chronic myeloid leukaemias: guidelines for distinguishing chronic granulocytic, atypical chronic myeloid, and chronic myelomonoctic leukaemia. Proposals by the FrenchAmerican-British cooperative leukaemia group. Br J Haematol. 1994;87:746-54.

8. Vardiman JW, Pierre R, Bain B, Bennett JM, Imbert M, Brunning $\mathrm{RD}$, et al. Chronic myelomonocytic leukemia. In: Jaffe ES, Harris NL, Stein H, Vardiman JW, editors. Pathology and genetics of tumous of haematopoietic and lymphoid tissues. IARC Press: Lyon; 2001. p. 49-52.

9. Orazi A, Bennett JM, Germing U, Brunning RD, Bain BJ, Thiele J Chronic myelomonocytic leukemia. In: Swerdlow SH, Campo E, Harris NL, et al., editors. WHO Classification fo Tumours of Haematopoietic and Lymphoid Tissues. Lyon: International Agency for Research on Cancer; 2008. p. 76-9.

10. Melo JV, Myint H, Galton DA, Goldman JM. P190BCR-ABL chronic myeloid leukaemia: the missing link with chronic myelomonocytic leukaemia? Leukemia. 1994;8:208-11.

11. Boiocchi L, Espinal-Witter R, Geyer JT, Steinhilber J, Bonzheim I, Knowles DM, et al. Development of monocytosis in patients with primary myelofibrosis indicates an accelerated phase of the disease. Mod Pathol. 2013;26:204-12.

12. Elliott MA, Verstovsek S, Dingli D, Schwager SM, Mesa RA, Li $\mathrm{CY}$, et al. Monocytosis is an adverse prognostic factor for survival in younger patients with primary myelofibrosis. Leuk Res. 2007;31:1503-9.

13. Tefferi A, Shah S, Mudireddy M, Lasho TL, Barraco D, Hanson $\mathrm{CA}$, et al. Monocytosis is a powerful and independent predictor of inferior survival in primary myelofibrosis. Br $\mathrm{J}$ Haematol. 2017;183:835-8.

14. Chapman J, Geyer JT, Khanlari M, Moul A, Casas C, Connor ST, et al. Myeloid neoplasms with features intermediate between primary myelofibrosis and chronic myelomonocytic leukemia. Mod Pathol. 2018;31:429-41.

15. Barraco D, Cerquozzi S, Gangat N, Patnaik MM, Lasho T, Finke $\mathrm{C}$, et al. Monocytosis in polycythemia vera: clinical and molecular correlates. Am J Hematol. 2017;92:640-5.

16. Bain BJ, Horny H-P, Arber DA, Tefferi A, Hasserjian RP. Myeloid/lymphoid neoplasms with eosinophilia and rearrangement of PDGFRA, PDGFRB or FGFR1 or with PCM1-JAK2. In: Swerdlow SH, Campo E, Harris NL, et al., editors. WHO Classification of Tumours of Haematopoietic and Lymphoid Neoplasms. Lyon: Inernational Agency for Research on Cancer; 2017. p. 72-9.
17. David M, Cross NC, Burgstaller S, Chase A, Curtis C, Dang R, et al. Durable responses to imatinib in patients with PDGFRB fusion gene-positive and BCR-ABL-negative chronic myeloproliferative disorders. Blood. 2007;109:61-4.

18. Goasguen JE, Bennett JM, Bain BJ, Vallespi T, Brunning R, Mufti GJ. Morphological evaluation of monocytes and their precursors. Haematologica. 2009;94:994-7.

19. Such E, Cervera J, Costa D, Sole F, Vallespi T, Luno E, et al. Cytogenetic risk stratification in chronic myelomonocytic leukemia. Haematologica. 2011;96:375-83.

20. Patnaik MM, Tefferi A. Cytogenetic and molecular abnormalities in chronic myelomonocytic leukemia. Blood Cancer J. 2016;6:e393.

21. Mason CC, Khorashad JS, Tantravahi SK, Kelley TW, Zabriskie MS, Yan D, et al. Age-related mutations and chronic myelomonocytic leukemia. Leukemia. 2016;30:906-13.

22. Palomo L, Garcia O, Arnan M, Xicoy B, Fuster F, Cabezon M, et al. Targeted deep sequencing improves outcome stratification in chronic myelomonocytic leukemia with low risk cytogenetic features. Oncotarget. 2016;7:57021-35.

23. Patel BJ, Przychodzen B, Thota S, Radivoyevitch T, Visconte V, Kuzmanovic T, et al. Genomic determinants of chronic myelomonocytic leukemia. Leukemia. 2017;31:2815-23.

24. Meggendorfer M, Jeromin S, Haferlach C, Kern W, Haferlach T. The mutational landscape of 18 investigated genes clearly separates four subtypes of myelodysplastic/myeloproliferative neoplasms. Haematologica. 2018;103:e192-5.

25. Jaiswal S, Fontanillas P, Flannick J, Manning A, Grauman PV, Mar BG, et al. Age-related clonal hematopoiesis associated with adverse outcomes. N Engl J Med. 2014;371:2488-98.

26. Genovese G, Kahler AK, Handsaker RE, Lindberg J, Rose SA, Bakhoum SF, et al. Clonal hematopoiesis and blood-cancer risk inferred from blood DNA sequence. $\mathrm{N}$ Engl $\mathrm{J}$ Med. 2014;371:2477-87.

27. Xie M, Lu C, Wang J, McLellan MD, Johnson KJ, Wendl MC, et al. Age-related mutations associated with clonal hematopoietic expansion and malignancies. Nat Med. 2014;20:1472-8.

28. Onida F, Kantarjian HM, Smith TL, Ball G, Keating MJ, Estey $\mathrm{EH}$, et al. Prognostic factors and scoring systems in chronic myelomonocytic leukemia: a retrospective analysis of 213 patients. Blood. 2002;99:840-9.

29. Schuler E, Schroeder M, Neukirchen J, Strupp C, Xicoy B, Kundgen A, et al. Refined medullary blast and white blood cell count based classification of chronic myelomonocytic leukemias. Leuk Res. 2014;38:1413-9.

30. Xicoy B, Triguero A, Such E, Garcia O, Jimenez MJ, Arnan M, et al. The division of chronic myelomonocytic leukemia (CMML)-1 into CMML-0 and CMML-1 according to 2016 World Health Organization (WHO) classification has no impact in outcome in a large series of patients from the Spanish group of MDS. Leuk Res. 2018;70:34-6.

31. Ricci C, Fermo E, Corti S, Molteni M, Faricciotti A, Cortelezzi A, et al. RAS mutations contribute to evolution of chronic myelomonocytic leukemia to the proliferative variant. Clin Cancer Res. 2010;16:2246-56.

32. Cervera N, Itzykson R, Coppin E, Prebet T, Murati A, Legall S, et al. Gene mutations differently impact the prognosis of the myelodysplastic and myeloproliferative classes of chronic myelomonocytic leukemia. Am J Hematol. 2014;89:604-9.

33. Loghavi S, Sui D, Wei $P$, Garcia-Manero G, Pierce $S$, Routbort MJ, et al. Validation of the 2017 revision of the WHO chronic myelomonocytic leukemia categories. Blood Adv. 2018;2:1807-16.

34. Padron E, Garcia-Manero G, Patnaik MM, Itzykson R, Lasho T, Nazha A, et al. An international data set for CMML validates 
prognostic scoring systems and demonstrates a need for novel prognostication strategies. Blood Cancer J. 2015;5:e333.

35. Onida F, Iacobelli S, Garcia-Manero G, Patnaik MM, Itzykson $\mathrm{R}$, Lasho TL, et al. A newly clinically-based subclassification proposal in CMML with significant prognostic implications to overcome the MDS/MPN categorizing dilemma. Blood. 2016;128:4320.

36. Petrova-Drus K, Chiu A, Margolskee E, Barouk-Fox S, Geyer J, Dogan A, et al. Bone marrow fibrosis in chronic myelomonocytic leukemia is associated with increased megakaryopoiesis, splenomegaly and with a shorter median time to disease progression. Oncotarget. 2017;8:103274-82.

37. Khan M, Muzzafar T, Kantarjian H, Badar I, Short N, Wang X, et al. Association of bone marrow fibrosis with inferior survival outcomes in chronic myelomonocytic leukemia. Ann Hematol. 2018;97:1183-91.

38. Gur HD, Loghavi S, Garcia-Manero G, Routbort M, KanagalShamanna R, Quesada A, et al. Chronic myelomonocytic leukemia with fibrosis is a distinct disease subset with myeloproliferative features and frequent JAK2p.V617F mutations. Am J Surg Pathol. 2018;42:799-806.

39. Geyer JT, Tam W, Liu YC, Chen Z, Wang SA, Bueso-Ramos C, et al. Oligomonocytic chronic myelomonocytic leukemia (chronic myelomonocytic leukemia without absolute monocytosis) displays a similar clinicopathologic and mutational profile to classical chronic myelomonocytic leukemia. Mod Pathol. 2017;30:1213-22.

40. Patnaik MM, Rangit V, Lasho TL, Hoversten KP, Finke CM, Ketterling RP, et al. A comparison of clinical and molecular characteristics of patients with systemic mastocytosis with chronic myelomonocytic leukemia to CMML alone. Leukemia. 2018;32:1850-6.

41. Vermi W, Facchetti F, Rosati S, Vergoni F, Rossi E, Festa S, et al. Nodal and extranodal tumor-forming accumulation of plasmacytoid monocytes/interferon-producing cells associated with myeloid disorders. Am J Surg Pathol. 2004;28:585-95.

42. Brunetti L, Di Battista V, Venanzi A, Schiavoni G, Martelli MP, Ascani S, et al. Blastic plasmacytoid dendritic cell neoplasm and chronic myelomonocytic leukemia: a shared clonal origin. Leukemia. 2017;31:1238-40.

43. Xu Y, McKenna RW, Karandikar NJ, Pildain AJ, Kroft SH. Flow cytometric analysis of monocytes as a tool for distinguishing chronic myelomonocytic leukemia from reactive monocytosis. Am J Clin Pathol. 2005;124:799-806.

44. Sojitra P, Gandhi P, Fitting P, Kini AR, Alkan S, Velankar MM, et al. Chronic myelomonocytic leukemia monocytes uniformly display a population of monocytes with $\mathrm{CD} 11 \mathrm{c}$ underexpression. Am J Clin Pathol. 2013;140:686-92.

45. Selimoglu-Buet D, Wagner-Ballon O, Saada V, Bardet V, Itzykson R, Bencheikh L, et al. Characteristic repartition of monocyte subsets as a diagnostic signature of chronic myelomonocytic leukemia. Blood. 2015;125:3618-26.

46. Patnaik MM, Timm MM, Vallapureddy R, Lasho TL, Ketterling RP, Gangat N, et al. Flow cytometry based monocyte subset analysis accurately distinguishes chronic myelomonocytic leukemia from myeloproliferative neoplasms with associated monocytosis. Blood Cancer J. 2017;7:e584.

47. Picot T, Aanei CM, Flandrin Gresta P, Noyel P, Tondeur S, Tavernier Tardy E, et al. Evaluation by flow cytometry of mature monocyte subpopulations for the diagnosis and follow-up of chronic myelomonocytic leukemia. Front Oncol. 2018;8:109.

48. Hudson CA, Burack WR, Leary PC, Bennett JM. Clinical utility of classical and nonclassical monocyte percentage in the diagnosis of chronic myelomonocytic leukemia. Am J Clin Pathol. 2018;150:293-301.

49. Selimoglu-Buet D, Badaoui B, Benayoun E, Toma A, Fenaux P, Quesnel B, et al. Accumulation of classical monocytes defines a subgroup of MDS that frequently evolves into CMML. Blood. 2017;130:832-5.

50. Cui Y, Tong H, Du X, Li B, Gale RP, Qin T, et al. Impact of TET2, SRSF2, ASXL1 and SETBP1 mutations on survival of patients with chronic myelomonocytic leukemia. Exp Hematol Oncol. 2015;4:14.

51. Elena C, Galli A, Such E, Meggendorfer M, Germing U, Rizzo E, et al. Integrating clinical features and genetic lesions in the risk assessment of patients with chronic myelomonocytic leukemia. Blood. 2016;128:1408-17.

52. Federmann B, Abele M, Rosero Cuesta DS, Vogel W, Boiocchi L, Kanz L, et al. The detection of SRSF2 mutations in routinely processed bone marrow biopsies is useful in the diagnosis of chronic myelomonocytic leukemia. Hum Pathol. 2014;45:2471-9.

53. Duchmann M, Yalniz FF, Sanna A, Sallman D, Coombs CC, Renneville A, et al. Prognostic role of gene mutations in chronic myelomonocytic leukemia patients treated with hypomethylating agents. EBioMedicine. 2018;31:174-81.

54. Patnaik MM, Barraco D, Lasho TL, Finke CM, Hanson CA, Ketterling RP, et al. DNMT3A mutations are associated with inferior overall and leukemia-free survival in chronic myelomonocytic leukemia. Am J Hematol. 2017;92:56-61.

55. Patnaik MM, Vallapureddy R, Lasho TL, Hoversten KP, Finke $\mathrm{CM}$, Ketterling R, et al. EZH2 mutations in chronic myelomonocytic leukemia cluster with ASXL1 mutations and their cooccurrence is prognostically detrimental. Blood Cancer J. 2018;8:12.

56. Patnaik MM, Lasho TL, Vijayvargiya P, Finke CM, Hanson CA, Ketterling RP, et al. Prognostic interaction between ASXL1 and TET2 mutations in chronic myelomonocytic leukemia. Blood Cancer J. 2016;6:e385.

57. Peng J, Zuo Z, Fu B, Oki Y, Tang G, Goswami M, et al. Chronic myelomonocytic leukemia with nucleophosmin (NPM1) mutation. Eur J Haematol. 2016;96:65-71.

58. Vallapureddy R, Lasho TL, Hoversten K, Finke CM, Ketterling R, Hanson C, et al. Nucleophosmin 1 (NPM1) mutations in chronic myelomonocytic leukemia and their prognostic relevance. Am J Hematol. 2017;92:E614-18.

59. Courville EL, Wu Y, Kourda J, Roth CG, Brockmann J, Muzikansky A, et al. Clinicopathologic analysis of acute myeloid leukemia arising from chronic myelomonocytic leukemia. Mod Pathol. 2013;26:751-61.

60. Papaemmanuil E, Gerstung M, Malcovati L, Tauro S, Gundem G, Van Loo P, et al. Clinical and biological implications of driver mutations in myelodysplastic syndromes. Blood. 2013;122:3616-27. quiz 3699

61. Montalban-Bravo G, Takahashi K, Patel K, Wang F, Xingzhi S, Nogueras GM, et al. Impact of the number of mutations in survival and response outcomes to hypomethylating agents in patients with myelodysplastic syndromes or myelodysplastic/ myeloproliferative neoplasms. Oncotarget. 2018;9:9714-27. 